\title{
A KINETIC STUDY ON THE INTERACTION BETWEEN TAZOBACTAM (A PENICILLANIC ACID SULPHONE DERIVATIVE) AND ACTIVE-SITE SERINE $\beta$-LACTAMASES
}

\author{
MARIAGRAZIA PERILLI ${ }^{a}$, NICOLA FRANCESCHINI ${ }^{\mathrm{a}}$, \\ GIOVANNI BONFIGLIO ${ }^{\mathrm{b}}$, BERNARDETTA SEGATORE ${ }^{\mathrm{a}}$, \\ STEFANIA STEFANI ${ }^{\mathrm{b}}$, GIUSEPPE NICOLETTI ${ }^{\mathrm{b}}$, \\ MARIA DEL MAR TAVIO PEREZ ${ }^{c}$, CIRO BIANCHI ${ }^{d}$, \\ ALESSANDRO ZOLLO $^{d}$ and GIANFRANCO AMICOSANTE ${ }^{a, *}$ \\ ${ }^{a}$ Department of Biomedical Sciences and Technologies, University of L'Aquila, \\ Loc. Coppito - 67100, L'Aquila, Italy; ' Institute of Microbiology, \\ University of Catania, Italy; 'Department of Clinical Sciences, \\ University of Gran Canaria, Las Palmas, Gran Canaria, Spain; \\ ${ }^{\mathrm{d}}$ Medical Department of Wyeth-Lederle, Roma, Italy
}

(Received 16 February 1999)

\begin{abstract}
The interaction between tazobactam and several chromosome- and plasmid-encoded (TEM, SHV, PSE types) class A and C $\beta$-lactamases was studied by spectrophotometry. Tazobactam behaved as a competitive inhibitor or inactivator able to restore in several cases the efficiency of piperacillin as a partner $\beta$-lactam. A detailed kinetic analysis permitted measurement of the acylation efficiency for some cephalosporinases and broad-spectrum $\beta$-lactamases; the presence of a turn-over of acyl-enzyme complex was also evaluated.
\end{abstract}

Keywords: $\beta$-lactamase; Inhibitor; Tazobactam; Kinetics

\section{INTRODUCTION}

The production of $\beta$-lactamase represents one of the major causes of resistance to $\beta$-lactam antibiotics. To date, two different strategies have been

\footnotetext{
*Corresponding author. Fax: $++39-862-433433$. E-mail: amicosante@axscaq.aquila.infn.it.
} 
used to overcome $\beta$-lactamase-mediated resistance: (i) development of B-lactamase-stable compounds such as metoximino cephalosporins, cephamycins, monobactams and carbapenems; (ii) use of suicide inhibitors associated with a $\beta$-lactam-labile antibiotic. The success of the latter strategy depends on the ability of the suicide inhibitor to inactivate the enzyme. The former approach has led to new forms of $\beta$-lactamase-mediated resistance such as stable derepression of class $C$ cephalosporinases or the emergence of extended spectrum variants of TEM, SHV and AmpC plasmid-derived families. ${ }^{1}$ Since these enzymes are able to determine resistance to many newer antibiotics there is a new interest in drugs inhibiting $\beta$-lactamase activity.

Despite enormous research efforts, only three compounds are widely used at the clinical level. Clavulanic acid was the first $\beta$-lactamase inhibitor to be introduced into clinical practice; two other compounds, sulbactam and tazobactam, are also used in therapy. Tazobactam has been reported to inhibit many of the most common $\beta$-lactamases; it is used in association with piperacillin which has intrinsically greater activity than other penicillins previously used in combination with inhibitors. ${ }^{2 \cdots 4}$

In the present study, we have evaluated the kinetic interactions between tazobactam and chromosome/plasmid-encoded $\beta$-lactamases belonging to class $\mathrm{A}$ and $\mathrm{C}$ active-site serine enzymes purified in our laboratory in order to determine the effectiveness of this inhibitor.

\section{METHODS}

\section{Chemicals, Media and Antimicrobials}

Chemicals were of the purest analytical grade and obtained from commercial sources. Culture media and nitrocefin were from Unipath, Milan, Italy. Tazobactam was kindly supplied by Lederle, Catania, Italy.

The strains used in this study were all clinical isolates coming from immunocompromised patients and belonged to the collection of the University of L'Aquila. The identification of the investigated strains was performed by conventional methods.

\section{In Vitro Susceptibility Testing}

Minimum inhibitory concentration (MIC) determinations for selected organisms were performed using macrodilution broth procedures and a final inoculum of $5 \times 10^{5} \mathrm{CFU} / \mathrm{ml}$ as recommended by the National Committee for Clinical Laboratory Standards reference manual. ${ }^{5}$ 


\section{Enzyme Purification}

The $\beta$-lactamases used in the present study are listed in Table I. The enzymes from Citrobacter diversus ULA-27, Mycobacterium fortuitum D316, Serratia marcescens TEM-AQ (Escherichia coli TEM-AQ), Acinetobacter baumannii ULA-187 and Providencia stuartii (E. coli TEM-60) were purified as previously reported. ${ }^{6-10}$ The enzyme from Morganella morganii MN89 was purified to homogeneity and the detailed procedures are reported elsewhere (Amicosante, unpublished data).

The $\beta$-lactamases produced by $E$. coli (PSE-1 and PSE-4), Pseudomonas aeruginosa PSE-2, Klebsiella pneumoniae ULA-4, (E. coli ULA-4, SHV-type by oligotyping), $P$. aeruginosa ULA-18 and $P$. aeruginosa ULA-21 were purified as follows. Bacteria were grown in BHI medium $(2 \mathrm{~L})$ for $18 \mathrm{~h}$ at $37^{\circ} \mathrm{C}$ with orbital shaking $(120 \mathrm{rpm})$. Cells were harvested by centrifugation at $10,000 \times g$ for $15 \mathrm{~min}$ at $4^{\circ} \mathrm{C}$, washed with $50 \mathrm{mM}$ sodium phosphate buffer $\mathrm{pH} 7.0$ and disrupted by sonication ( 4 cycles of $40 \mathrm{~s}, 60 \mathrm{~W}$, in ice bath). Crude extracts were centrifuged at $105,000 \times \mathrm{g}$ for $30 \mathrm{~min}$ and the cleared supernatants of PSE-1, PSE-2 and PSE-4 were dialysed overnight against $30 \mathrm{mM}$ Tris- $\mathrm{HCl}$ buffer $\mathrm{pH} 8.0$. The material was then loaded onto a Sepharose Q FF column (XK 26/20, Pharmacia Biotech, Milan, Italy), equilibrated with the same buffer. The crude extracts of E. coli ULA-4, P. aeruginosa ULA-18 and $P$. aeruginosa ULA-21 were separately loaded onto a Sepharose S-FF column equilibrated with the sodium/potassium phosphate buffer $50 \mathrm{mM}$ pH 6.8 . The $\beta$-lactamases were eluted at $3 \mathrm{ml} / \mathrm{min}$ over a linear gradient $0-0.5 \mathrm{M} \mathrm{NaCl}$ in $60 \mathrm{~min}$. The active fractions were pooled and loaded onto a Superdex 75 (XK 26/70 Pharmacia Biotech, Milan, Italy)

TABLE I Main characteristics of the $\beta$-lactamases used in this study

\begin{tabular}{llccr}
\hline Enzyme source & Gene location & Molecular class* & $\mathrm{Km}^{\S}(\mu \mathrm{M})$ & $\mathrm{p} I$ \\
\hline C. diversus ULA-27 & Chromosome & $\mathrm{A}^{6}$ & $20^{\mp}$ & 6.8 \\
M. fortuitum D316 & Chromosome & $\mathrm{A}^{18}$ & 115 & 4.9 \\
E. coli TEM-AQ & Plasmid-ESBL & $\mathrm{A}^{8}$ & 120 & 5.5 \\
E. coli TEM-60 & Plasmid-ESBL & $\mathrm{A}^{10}$ & 20 & 6.4 \\
E. coli ULA-4 & Plasmid-ESBL & $\mathrm{A}^{\dagger}$ & 25 & 8.5 \\
E. coli PSE-1 & Plasmid & $\mathrm{A}^{1}$ & 48 & 5.7 \\
E. coli PSE-4 & Plasmid & $\mathrm{A}^{1}$ & 53 & 5.4 \\
A. baumannii ULA-187 & Chromosome & $\mathrm{C}^{9}$ & 50 & $>9.0$ \\
M. morganii MN89 & Chromosome & $\mathrm{C}$ & 120 & 6.3 \\
P. aeruginosa ULA-18 & Chromosome & Undetermined & 200 & $>9.0$ \\
$P$. aeruginosa ULA-21 & Chromosome & Undetermined & 45 & $>9.0$ \\
\hline
\end{tabular}

* According to the Ambler's classification. ${ }^{18+}$ SHV-type hybridization. ${ }^{\ddagger} \mathrm{ES} \beta \mathrm{L}=$ extended spectrum $\beta$-lactamase. "For $C$. diversus ULA-27, cefazoline was used as a substrate reporter. ${ }^{8} \mathrm{Km}$ values of nitrocefin which were used as reporter substrate. 
equilibrated with $50 \mathrm{mM}$ sodium phosphate buffer $\mathrm{pH} 7.0$. The fractions exhibiting $\beta$-lactamase activity were concentrated by ultrafiltration with YM10 membranes (cutoff $10 \mathrm{kDa}$ ) (Amicon Corp., Beverly, Mass.).

The purity of enzymes was determined by SDS-polyacrilamide gel electrophoresis analysis performed by the method of Laemmli ${ }^{11}$ and each enzyme was estimated to be at least $90 \%$ pure (data not shown).

\section{Determination of $\boldsymbol{\beta}$-Lactamase Activity}

The $\beta$-lactamase activity was monitored in a Perkin-Elmer Lambda 2 spectrophotometer by measuring the hydrolysis of $100 \mu \mathrm{M}$ nitrocefin $\left(\Delta \varepsilon_{M}^{482}=\right.$ $15,000 \mathrm{M}^{-1} \mathrm{~cm}^{-1}$ ) at $482 \mathrm{~nm}$. One enzyme unit represents the amount of protein that hydrolyses $1 \mu \mathrm{mol}$ of nitrocefin per minute at $30^{\circ} \mathrm{C}$ in $50 \mathrm{mM}$ sodium phosphate buffer $\mathrm{pH}$ 7.0. The protein concentration was estimated by the method of Bradford ${ }^{12}$ using bovine serum albumin as standard.

\section{Enzyme Inhibition Studies}

The interaction of tazobactam with each enzyme was studied using 100$200 \mu \mathrm{M}$ nitrocefin or cefazoline as reporter substrate. ${ }^{13}$ The inhibition constant $K_{\mathrm{i}}$, when a competitive model was assessed, was determined at various tazobactam concentrations by measuring the initial rate of substrate hydrolysis with or without inhibitor. Under these conditions, a plot of $v_{0} / v_{\mathrm{i}}$ versus tazobactam concentration yielded a straight line whose slope was $K_{\mathrm{m}}$ / $\left(K_{\mathrm{m}}+S\right) \times K_{\mathrm{i}}$

\section{Tazobactam Behaving as Poor Substrate}

When tazobactam behaved as a poor substrate, the $k_{\text {cat }}$ value was determined from the initial rate at saturating substrate concentration $(250 \mu \mathrm{M})$ and the $\mathrm{Km}$ value was calculated as $K_{\mathrm{i}}$.

\section{Tazobactam Behaving as Transient Inhibitor}

The accumulation of the acyl-enzyme $\left(\mathrm{EC}^{*}\right)$ allowed calculation of the individual kinetic constants on the basis of the following scheme:

$$
\mathrm{E}+\mathrm{C} \stackrel{K}{\Leftrightarrow} \mathrm{EC} \stackrel{k_{+2}}{\rightarrow} \mathrm{EC}^{\times} \stackrel{k_{+3}}{\rightarrow} \mathrm{E}+\mathrm{P}
$$


where $k_{+2}$ and $k_{+3}$ are the first-order acylation and deacylation constants and $K$ the dissociation constant of the Henri-Michaelis complex.

The individual parameters $k_{+2}, k_{+3}$ and $K$ of the reaction were derived from the dependence of $k_{\mathrm{i}}$ (first-order rate constant relative to the $\mathrm{EC}^{*}$ accumulation) versus tazobactam concentration as reported by Frère et al. ${ }^{14}$ and Galleni et al. ${ }^{15}$ on the basis of the following equation:

$$
k_{\mathrm{i}}=k_{+3}+k_{+2}[\mathrm{C}] /[\mathrm{C}]+K\left(K_{\mathrm{m}}+[\mathrm{S}] / K_{\mathrm{m}}\right)
$$

where [S] and $K_{\mathrm{m}}$ represent the concentration and the $\mathrm{Km}$ of the reporter substrate respectively.

Linear variations of $k_{\mathrm{i}}$ versus tazobactam concentrations indicated that the range of inhibitor concentrations used was below $K$; the $k_{+2} / K$ and $k_{+3}$ values were calculated as slope of the line and the extrapolation to $I=0$ respectively.

When possible, the $k_{+3}$ value was also calculated by direct hydrolysis of tazobactam at $233 \mathrm{~nm}\left(\Delta \varepsilon_{M}^{233}=+3600 \mathrm{M}^{-1} \mathrm{~cm}^{-1}\right)$ in the presence of large quantities of enzyme.

When tazobactam behaved as an inactivator the kinetic constants were derived as reported above. If a measurable $k_{+3}$ was observed, the value was calculated by monitoring the complete enzyme reactivation after incubation with the inhibitor at $1: 1000$ ratio. Aliquots $(5 \mu l)$ were withdrawn and diluted in $600 \mu \mathrm{l}$ of buffered $200 \mu \mathrm{M}$ nitrocefin ( 120 fold dilution).

\section{RESULTS}

In Table II, we report the kinetic values for the PSE, TEM and SHV derived enzymes with tazobactam. Regarding the PSE $\beta$-lactamases (Table II) (of clinical relevance in $P$. aeruginosa) we were able to measure the acylation efficiency value for PSE-4 enzyme. After prolonged incubation (30 min), the acyl-enzyme complex regained enzyme activity, the half-life of the complex E-I was estimated as around $2 \mathrm{~h}$. The PSE-1 enzyme has a high affinity for tazobactam $\left(K_{\mathrm{i}}=10 \mu \mathrm{M}\right)$.

Concerning the TEM-derived enzymes, TEM-AQ hydrolysed tazobactam and a $k_{\text {cat }}$ value was measured by direct hydrolysis; on the basis of the $k_{\text {cat }} / K$ ratio the compound could be considered as a substrate equivalent to benzylpenicillin. The TEM-60 from $P$. stuartii, was acylated in a very fast manner and the rate was not measurable because the E-I complex formation occurred within the dead-time of the reaction. Moreover, the half-life of the E-I 
TABLE II Tazobactam as poor substrate

\begin{tabular}{lccc}
\hline Enzymes & $\mathrm{Km}^{*}(\mu \mathrm{M})$ & $k_{\text {cat }}\left(\mathrm{s}^{-1}\right)$ & $k_{\text {cal }} / \mathrm{Km}\left(\mathrm{M}^{-1} \mathrm{~s}^{-1}\right)$ \\
\hline E. coli PSE-1 & 10 & $\mathrm{n} \cdot \mathrm{d}$. & $<10$ \\
E. coli TEM-AQ & 0.34 & $8 \cdot 10^{-2}$ & $2.3 \cdot 10^{5}$ \\
E. coli TEM-60 & $1.8 \cdot 10^{-2}$ & $4.2 \cdot 10^{-4}$ & $2.3 \cdot 10^{4}$ \\
E. coli $(\mathrm{SHV})$ & $1.2 \cdot 10^{-2}$ & $<10^{-4}$ & $<8.4 \cdot 10^{3}$ \\
\hline
\end{tabular}

n.d. $=$ not determined. SD values were below $10 \%$. ${ }^{*} \mathrm{Km}$ deternined as $K_{\mathrm{i}}$.

TABLE III Tazobactam as transient inactivator or inactivator of class $\mathrm{A}$ and $\mathrm{C} \beta$-lactamases

\begin{tabular}{lccccc}
\hline Enzymes & $K_{\mathrm{i}}(\mu \mathrm{M})$ & $k_{+-2} K\left(\mathrm{M}^{-1} \mathrm{~s}^{-1}\right)$ & $k_{+3}\left(\mathrm{~s}^{-1}\right)$ & $K(\mu \mathrm{M})$ & $k_{+2}\left(\mathrm{~s}^{-1}\right)$ \\
\hline C. diversus ULA-27 & n.d. & $1.9 \cdot 10^{3}$ & Noturn-over & 1.2 & $2.2 \cdot 10^{-3}$ \\
M. fortuitum D316 & 20 & $1.1 \cdot 10^{3}$ & $1.4 \cdot 10^{-2}$ & n.d. & n.d. \\
$E$. coli PSE-4 & $6.7 \cdot 10^{-2}$ & $2.9 \cdot 10^{4}$ & $1.3 \cdot 10^{-3}$ & $6.9 \cdot 10^{-1}$ & $2.0 \cdot 10^{-2}$ \\
$M$. morgamii MN-89 & 2.3 & $8.2 \cdot 10^{2}$ & Noturn-over & n.d. & n.d. \\
A. baumannii ULA-187 & $3.3 \cdot 10^{2}$ & 62 & No turn-over & 26 & $1.6 \cdot 10^{-2}$ \\
$P$. aeruginosa ULA-18 & $31^{*}$ & $1.3 \cdot 10^{2}$ & $4.1 \cdot 10^{-3}$ & n.d. & n.d. \\
$P$. aeruginosa ULA-21 & $18^{*}$ & $1.1 \cdot 10^{2}$ & $2.0 \cdot 10^{-3}$ & n.d. & n.d. \\
\hline
\end{tabular}

n.d. $=$ not determined. SD values were below $10 \%$. ${ }^{*} K_{\mathrm{i}}$ calculated equal to $k_{+3} K / k_{+2}$.

complex was calculated as $40 \mathrm{~min}$, a time sufficient to restore the efficiency "in vivo" of a partner $\beta$-lactam such as piperacillin.

The SHV-derived ES $\beta$ L from $K$. pneumoniae ULA-4 was competitively inhibited with a $K_{\mathrm{i}}$ value similar to that for the TEM-60 enzyme. As reported in Table III, the PSE-4 class $A$-lactamase was efficiently acylated by tazobactam and we could compute all the individual kinetic constants (Figures 1-3). A turn-over was observed and the $k_{+3}$ could be estimated to be equal to $1.3 \cdot 10^{-3} \mathrm{~s}^{-1}$. Moreover, the calculated $k_{\mathrm{i}}$ value $\left(k_{\mathrm{i}}=k_{+3} K / k_{+2}=\right.$ $0.044 \mu \mathrm{M}$ ) was in good agreement with the $K_{\mathrm{i}}$ determined at the steady-state $\left(K_{\mathrm{i}}=0.067 \mu \mathrm{M}\right)$. The two chromosome-encoded class A enzymes produced by $C$. diversus ULA-27 and $M$. fortuitum D316 respectively showed similar low values of acylation efficiency $\left(k_{+2} / K=10^{3} \mathrm{M}^{-1} \mathrm{~s}^{-1}\right)$. The $M$. fortuitum D316 was transiently inactivated. The acylation efficiency of the enzyme was determined by studying a plot of the $k_{i}$ values versus different tazobactam concentrations. Figure 3 where a linear dependence of $k_{\mathrm{i}}$ was obtained; the $k_{+2} / K$ was computed as the slope of the curve. The persistence of the enzyme-inhibitor complex $(E-1)$ at the steady-state before the breakdown occurred was estimated to be $72 \mathrm{~s}$ (half-life) for $M$. fortuitum $\beta$-lactamase. In the case of $C$. diversus ULA-27 enzyme, the result indicated a process of inactivation without turn-over. Similarly for the class $C$ enzyme, 


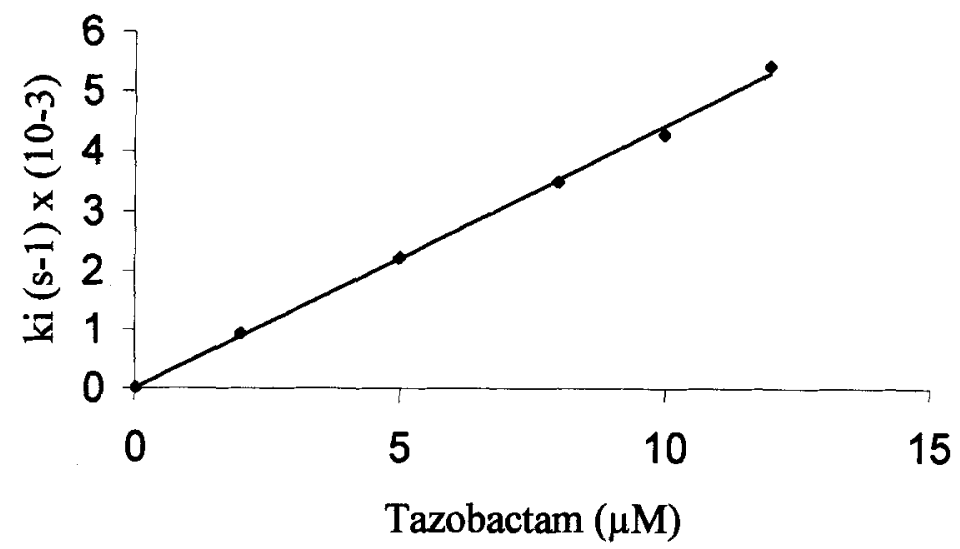

FIGURE 1 Inactivation rate constant $\left(k_{\mathrm{i}}\right)$ of $M$. morganii MN89 class $\mathrm{C} \beta$-lactamase as a function of tazobactam concentration. The plot represent the fitting of data with $k_{+3}=0$.

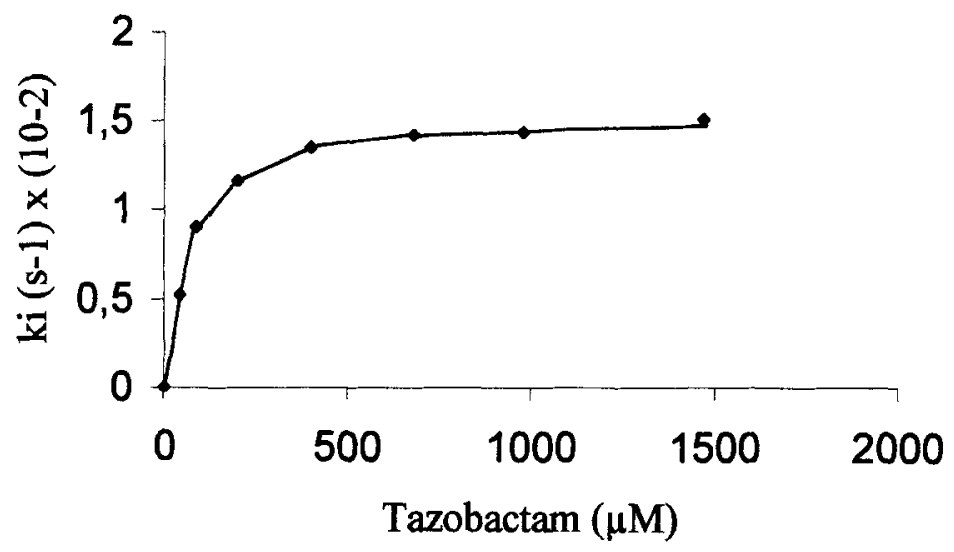

FIGURE 2 Variation of the inactivation rate constant $\left(k_{\mathrm{j}}\right)$ versus tazobactam concentration for $A$. baumannii ULA-187 class C $\beta$-lactamase.

$M$. morganii MN-89 and $A$. baumannii ULA-187 inactivation occurred but no turn-over was detected. $M$. morganii inactivation constants $k_{\mathrm{i}}$ were linearly dependant on the tazobactam concentration (Figure 1) and the $k_{+2} / K$ value could be estimated. For $A$. baumannii the plot of $k_{\mathrm{i}}$ versus tazobactam concentration gave a hyperbolic curve (Figure 2). Under these conditions, we were able to calculate the individual kinetic constants $k_{+2}$ and $K$ (Table III). Tazobactam behaved as a poor inactivator $\left(k_{+2} / K=<200 \mathrm{M}^{-1} \mathrm{~s}^{-1}\right)$ for $P$. aeruginosa ULA-18 and ULA-21 cephalosporinases. In both systems 


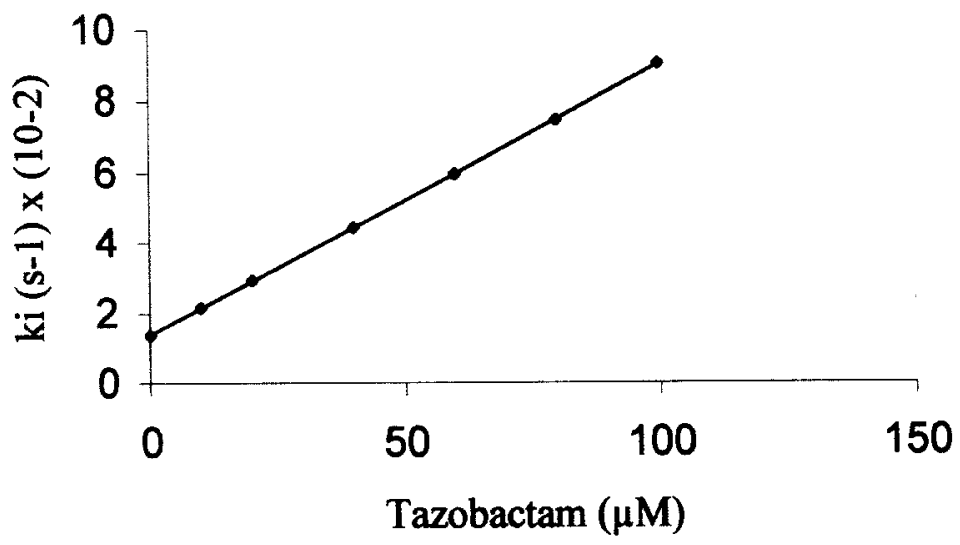

FIGURE 3 Inactivation rate constant $k_{\mathrm{i}}$ of $M$. fortuitum D316 class A $\beta$-lactamase as a function of tazobactam concentration. The plot represents the fitting of data with $k_{+3} \neq 0$.

TABLE IV MICs relative to piperacillin and piperacillin-tazobactam combinations towards selected strains used in this work

\begin{tabular}{lcc}
\hline Strain & Piperacillin $(\mu \mathrm{g} / \mathrm{ml})$ & Piperacillin-tazobactam $^{*}(\mu \mathrm{g} / \mathrm{ml})$ \\
\hline A. baumannii ULA-187 & 64 & 1 \\
E. coli Bla-div & $>256$ & 16 \\
E. coli TEM-AQ & $>256$ & 16 \\
E. coli TEM-60 & 256 & 1 \\
E. coli PSE-1 & $>256$ & 8 \\
E. coli PSE-4 & $>256$ & 4 \\
E. coli ULA-4 & 64 & $<0.5$ \\
\hline
\end{tabular}

* Tazobactam was used at $4 \mu \mathrm{g} / \mathrm{ml}$

a transient inactivation phenomenon was observed and a small turn-over could be measured. Moreover, a putative $K_{\mathrm{i}}$ value could be calculated as $K_{\mathrm{i}} \cong k_{+3} K / k_{+2}$.

In Table IV are reported the "in vitro" activities of piperacillin and piperacillin-tazobactam combination against the selected strains. All the bacteria are resistant to piperacillin except $E$. coli TEM-AQ; tazobactam restores the susceptibility of the other studied strains.

\section{DISCUSSION}

Several studies have demonstrated that inhibitors actively working against cell-free enzymes could have their potential reduced in the presence of a permeability barrier and this point cannot be considered a trivial issue when 
low-permeable species are encountered in clinical environments. As pointed out by Livermore, ${ }^{3}$ several factors should be assessed in order to elucidate the usefulness of $\beta$-lactam-inhibitor combinations against $\beta$-lactamase-producing strains. Akova et al. ${ }^{2}$ reported a comparison between clavulanic acid and tazobactam as inhibitors and inducers of AmpC-type $\beta$-lactamases in $P$. aeruginosa, E. cloacae, $C$. freundii, $S$. marcescens and $M$. morganii strains. The authors concluded that tazobactam was able to inhibit cephalosporinases and restore the microbiological activity of piperacillin. However, the inhibitory activity was reduced against $P$. aeruginosa and $E$. cloace $a$ strains.

Despite several hundreds of reports on susceptibility testing with $\beta$-lac$\operatorname{tam} / \beta$-lactamase inhibitor combinations only a few researchers described in detail the kinetic interactions between tazobactam and $\beta$-lactamases. ${ }^{16}$ Bush et al. ${ }^{17}$ reported parameters relevant to various molecular classes of $\beta$-lactamases and noted that the $I_{50}$ for the P99 cephalosporinase was 3-fold higher than the $K_{\mathrm{i}}$ for $M$. morganii enzyme and several-fold lower than the $K_{\mathrm{i}}$ value reported for the $A$. baumannii enzyme.

The use of $\beta$-lactams in combination with a $\beta$-lactamase inhibitor is reduced because of the catalytic heterogeneity of serine-active site $\beta$-lactamases mainly present in Gram-negative bacteria and with reduced permeability. The appearance of metallo- $\beta$-lactamases (Ambler Class B enzymes) able to hydrolyse inhibitors poses a great concern for the future of antibacterial chemotherapy.

This study analysed in detail the kinetic interaction between tazobactam and several class $\mathrm{A}$ and $\mathrm{C} \beta$-lactamases purified in our laboratory. MIC results indicated that tazobactam was a useful inhibitor to restore piperacillin susceptibility towards all the tested strains. Kinetics parameters relative to the enzyme inactivation by tazobactam showed these to be quite heterogenous. With chromosomal $\beta$-lactamases from $C$. diversus ULA-27, $M$. morganii MN89 an $A$. baumannii ULA-187 no turn-over was detected even if acylation efficiency $\left(k_{+2} / K\right)$ was 52 -fold higher in $C$. diversus ULA-27 with respect to $A$. baumannii ULA-187. The $\beta$-lactamases produced by $M$. fortuitum D316 and $P$. aeruginosa ULA-18 and ULA-21 seemed quite different regarding the acylation (measured as $k_{+3}$ ) which is not negligible and 10-fold larger with respect to the $C$. diversus ULA-27 enzyme.

The plasmid-encoded $\beta$-lactamases as reported in Table II appear to be really heterogenous with respect to the interaction with the inhibitor. This finding leads to the conclusion that the appearance of new TEM-derived enzymes or the diffusion of chromosome-encoded enzymes able to hydrolyse inactivators or insensitive could represent a real problem in the therapy of bacterial-associated infections. 


\section{Acknowledgements}

The financial support of the Ministero della Ricerca Scientifica e Tecnologica (M.U.R.S.T. 60\%, Italy) and the Consiglio Nazionale delle Ricerche (Italy) is gratefully acknowledged.

\section{References}

[1] K. Bush, G.A. Jacoby and A.A. Medeiros (1995) Antimicrob. Agents Chemother., 39(6), $1213 \cdots 1233$

[2] M. Akova, Y. Yang and D.M. Livermore (1990) J. Antimicrob. Chemother, 25, 199-208.

[3] D.M. Livermore (1993) J. Antimicrob. Chemother.. 31(Suppl. A.), 9-21.

[4] D.M. Livermore, H.Y. Chen and G. Bonfiglio (1992) Fortschr. Antimikrob. Antineoplast. Chemotherapie, 11, 379-388.

[5] National Committee for Clinical Laboratory Standards (1990) Reference methods for the determination of minimum inhibitory concentrations (MICs) of aerobic bacteria by broth macrodilution, broth mictodilution, and agar dilution. Approved Standard M7-A2. National Committee for Clinical Laboratory Standards, Villanova, Pa.

[6] G. Amicosante, A. Oratore. N. Franceschini. M. Maccarrone, R. Strom, M. Galleni et al. (1988) Biochem. J., 254.885 890.

[7] G. Amicosante, N. Franceschini, B. Segatore, A. Oratore. L. Fattorini, G. Orefici et al. (1990) Biochem. J., 271, 729-734

[8] M. Perilli, A. Felici, N. Franceschini. A. De Santis, L. Pagani, F. Luzzaro, A. Oratore, G.M. Rossolini, J.R. Knox and G. Amicosante (1997) Antimicrob. Agents Chemother., 41(11), 2374-2382.

[9] M. Perilli, A. Felici, A. Oratore, G. Cornaglia, G. Bonfiglio, G.M. Rossolini et al. (1996) Antimicrob. Agents Chemother., 40.715-719.

[10] N. Franceschini. M. Perilli, B. Segatore, D. Setacci, G. Amicosante, A. Mazzariol and G. Cornaglia (1998) Antimicrob. Agents Chemother., 42(6), 1459-1462.

[11] U.K. Laemmli (1970) Nature (Lond.), 227, 680-685.

[12] M.M. Bradford (1976) Anal. Biochem., 72, 248-254.

[13] F. De Meester, B. Joris, G. Reckinger, C. Bellefroid-Bourguignon and J.M. Frère (1997) Biochem. Pharmacol., 14, 2393-2403.

[14] J.M. Frère. C. Dormans, V.M. Lenzini and C. Duychaerts (1982) Biochem. J., 207, $429-436$.

[15] M. Galleni, N. Franceschini, B. Quinting, L. Fattorini, G. Orefici, A. Oratore et al (1994) Antimicrob. Agents Chemother., 38, 1608-1614.

[16] E.E. Stobberingh (1990) Chemotherapy, 36, 209-214.

[17] K. Bush, C. Macalintal. B.A. Rasmussen. V.J. Lee and Y. Yang (1993) Antimicrob. Agents Chemother., 37, 851-858.

[18] R.P. Ambler (1980) Phil. Trans. Roy. Soc. Ser. B. 289, $321-331$. 